\title{
Carboxylic acids: effective inhibitors for calcium sulfate precipitation?
}

\author{
Taher Rabizadeh ${ }^{1, *}$, Caroline L. Peacock $^{1}$ and Liane G. Benning ${ }^{1,2, *}$ \\ 1 Cohen Geochemistry Laboratory, School of Earth and Environment, University of Leeds LS2 9JT, UK \\ 2 GFZ German Research Centre for Geosciences, Telegrafenberg, D-14473 Potsdam, Germany
}

[Received 1 May 2014; Accepted 19 November 2014; Associate Editor: T. Rinder]

\section{ABSTRACT}

Results are reported here of an investigation into the effects of three carboxylic acid additives (tartaric, maleic and citric acids) on the precipitation of calcium sulfate phases. Precipitation reactions were followed at $\mathrm{pH} 7$ in the pure $\mathrm{CaSO}_{4}$ system and in experiments with $0-20 \mathrm{ppm}$ carboxylic acids added using in situ UV-VIS spectrophotometry (turbidity). The solid products were characterized in terms of their mineralogical composition, using X-ray diffraction, during and at the end of each reaction, and in terms of their morphological features, by scanning electron microscopy. All additives increased the time needed for turbidity to develop (induction time, start of precipitation) and the comparison between additive and additive-free experiments showed that, at equivalent concentrations, citric acid performed far better than the other two carboxylic acids. In all cases bassanite precipitated first and with time it transformed to gypsum. The addition of citrate stabilized bassanite and changed the final gypsum habit from typical needle-like crystals in the pure $\mathrm{CaSO}_{4}$ system to plates in the citrate-additive experiments.

KeYwords: gypsum, bassanite, carboxylic acids, inhibition, crystallization.

\section{Introduction}

CAlCium sulfates are important rock-forming minerals that occur in thick evaporitic deposits throughout geological history (Kinsman, 1969). In the calcium sulfate system three phases with various degrees of hydration exist: the dihydrate, gypsum $\left(\mathrm{CaSO}_{4} \cdot 2 \mathrm{H}_{2} \mathrm{O}\right)$, the hemihydrate, bassanite $\left(\mathrm{CaSO}_{4} \cdot 0.5 \mathrm{H}_{2} \mathrm{O}\right)$ and the anhydrous anhydrite $\left(\mathrm{CaSO}_{4}\right)$. The stability and formation of these phases are very temperature- and concentrationdependent (Freyer and Voigt, 2003). Between ambient temperature and $\sim 40^{\circ} \mathrm{C}$ the most stable phase is gypsum. With increasing ion concentrations and/or temperature, the solubilities of bassanite and anhydrite decrease leading to the dehydration of gypsum and its transformation to less hydrous polymorphs (Freyer and Voigt,

*E-mail: eetr@leeds.ac.uk

L.G.Benning@leeds.ac.uk

DOI: 10.1180/minmag.2014.078.6.13
2003). The mechanisms controlling the nucleation and growth of gypsum from aqueous solutions have gained renewed interest recently, however, because gypsum probably does not form directly from solution. One study (Wang et al., 2012) has suggested that gypsum forms through nonclassical nucleation via an amorphous calcium sulfate intermediate, while another study (Van Driessche et al., 2012) suggested that gypsum forms not through amorphous precursors but through the initial precipitation of nanocrystalline bassanite particles that self-assemble into larger gypsum crystals through oriented attachment.

The gypsum formation pathway is important because among calcium sulfates, gypsum is mined extensively for use as the crucial component in

This paper is published as part of a special issue in Mineralogical Magazine, Vol. 78(6), 2014 entitled 'Mineral-fluid interactions: scaling, surface reactivity and natural systems'. 
plasters and cements (e.g. Camarini and De Milito, 2011); to make plasters, gypsum has to be dehydrated to bassanite through the use of large amounts of energy. Equally important however, is the fact that in several industrial processes that rely on water-handling systems (e.g. oil and gas production, water desalination; Moghaddasi et al., 2006; Rahardianto et al., 2008), the precipitation of calcium sulfate phases leads to the deposition of minerals in pipes, filters and heat exchangers, forming mineral scales. Cleaning or removing such mineral scales is costly and undesirable and affects the efficiency and lifetime of processing technologies (e.g. Mi and Elimelech, 2010).

In order to reduce or mitigate calcium sulfate scaling, various simple anti-scaling approaches have been suggested, the most common being the use of inorganic (e.g. $\mathrm{Mg}^{2+}$; Guan et al., 2010) or organic additives (e.g. sulfonic, phosphonic or carboxylic compounds; Shakkthivel and Vasudevan, 2006; Prisciandaro et al., 2005; Akyol et al., 2009). The main requirements for an effective additive are that: (1) it is readily available; (2) it is effective at low concentrations; (3) it is cheap and its addition will not significantly affect production costs; (4) ideally it is biodegradable or non-toxic to the environment; and (5) it reduces mineral formation or prevents nucleated phases from adhering to surfaces of crucial production apparatus. Among additives fulfilling many of the above requirements are carboxylic acids (Hasson et al., 2011; Cao et al., 2014). To date, studies that have tested the effects of carboxylic acids on calcium sulfate precipitation have primarily evaluated changes in precipitation onset or the effect of high temperatures (Prisciandaro et al., 2005; Senthilmurugan et al., 2010; Ling et al., 2012; Amjad and Koutsoukos, 2014). Missing is a mechanistic understanding of the effects of variable concentrations of carboxylic acid and/or various carboxylic acid moieties.

To address this gap results are presented here on the effects of three carboxylic acids (citric, maleic and tartaric) and variable additive concentrations $(0-20 \mathrm{ppm})$ on the kinetics and phase morphologies that develop during homogeneous calcium sulfate formation reactions and derive a more mechanistic understanding of the processes.

\section{Experimental methods}

Inhibitor-free calcium sulfate precipitates (termed 'pure $\mathrm{CaSO}_{4}$ ' hereafter) were produced by mixing equal volumes of a $100 \mathrm{~mm} \mathrm{CaCl} 2 \cdot 2 \mathrm{H}_{2} \mathrm{O}$ solution and a $100 \mathrm{~mm} \mathrm{Na}_{2} \mathrm{SO}_{4}$ solution $(99 \%$ purity, VWR) at room temperature $\left(21^{\circ} \mathrm{C}\right)$ and under constant and continuous stirring. The mixed solutions were supersaturated with respect to gypsum (saturation index $\mathrm{SI}_{\mathrm{Gyp}}=0.5$ ) but undersaturated with respect to bassanite $\left(\mathrm{SI}_{\mathrm{Bas}}=\right.$ -0.37 ). The saturation indices (the logarithm of the ion activity product over the solubility product) and the related solubility products $\left(\mathrm{K}_{\text {sp.gypsum }}=10^{-3.66}\right.$ and $\left.\mathrm{K}_{\text {sp.bassanite }}=10^{-4.53}\right)$ were calculated by means of the geochemical computer code PHREEQC using the LLNL database (Parkhurst and Appelo, 1999).

Carboxylic acids (citric, maleic or tartaric acid; 99-100\%, VWR) were added to the initial sodium sulfate solution at concentrations of between 5 and $20 \mathrm{ppm}$. In all experiments, prior to mixing, the $\mathrm{pH}$ of the initial solutions was adjusted to 7, with $0.1 \mathrm{M} \mathrm{NaOH}$.

The kinetics of the reactions in the absence and presence of carboxylic acids was monitored through the development of turbidity in the mixed solutions as measured using a UV-VIS spectrophotometer (Uvikon XL) at $520 \mathrm{~nm}$. Reactions were followed in triplicate at room temperatures for up to $4 \mathrm{~h}$ and the variations in the turbidity onset from the three repeats are reported in minutes. At intermediate time steps and at the end of each experiment the solutions were quench-filtered $(0.2 \mu \mathrm{m})$ under vacuum with isopropanol and the solids retrieved. These solids were characterized mineralogically using powder X-ray diffraction (XRD; Bruker D8 diffractometer; $\mathrm{CuK} \alpha 1 ; 5-30^{\circ} 2 \theta ; 0.105^{\circ} 2 \theta /$ step), while the morphology of the phases formed was imaged using a field emission gun scanning electron microscope (FEG-SEM, FEI Quanta $650,3 \mathrm{kV})$.

\section{Results}

Turbidity developed in all of the experiments but the onset of turbidity occurred after different periods of time (induction times) that were dependent on additive type and concentration. Comparing the turbidity curve from the pure $\mathrm{CaSO}_{4}$ experiment with equivalent curves from experiments where $20 \mathrm{ppm}$ of the three carboxylic acids were added (Fig. 1), revealed a carboxylic acid-dependent increase in induction time. In the pure $\mathrm{CaSO}_{4}$ system, the first increase in turbidity was observed after $6 \pm 1 \mathrm{~min}$ and the increase in absorbance took $\sim 60$ min to reach a steady value 


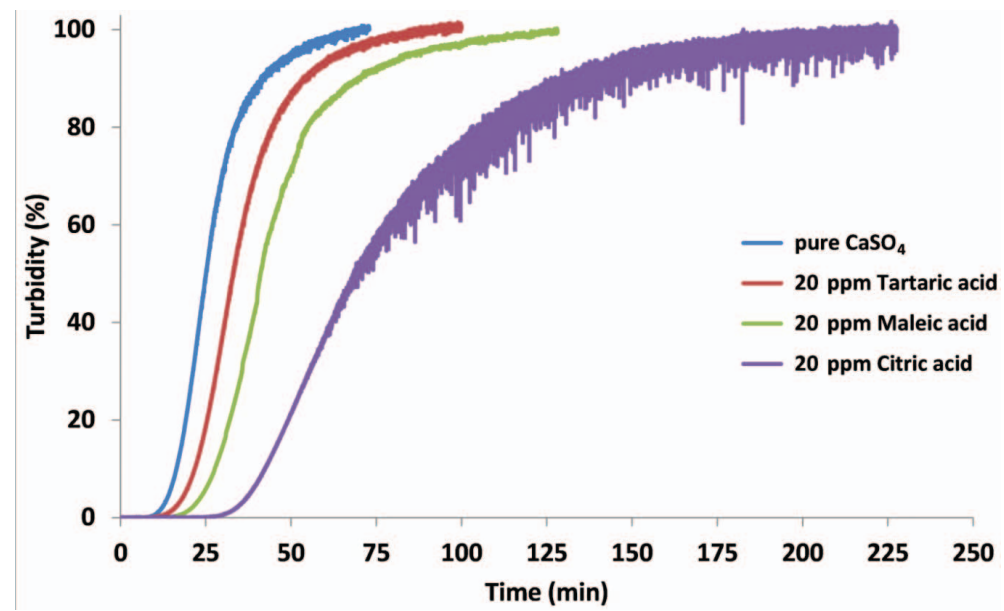

FIG. 1. The effect of adding $20 \mathrm{ppm}$ tartaric, maleic or citric acid on the development of turbidity compared to the pure $\mathrm{CaSO}_{4}$ system.

on a plateau. In the presence of $20 \mathrm{ppm}$ carboxylic acids the induction times increased to $9 \pm 1 \mathrm{~min}$, $16 \pm 1 \mathrm{~min}$ and $25 \pm 1 \mathrm{~min}$ for tartaric, maleic and citric acid, respectively, and specifically in the case of added citric acid the reaction curve took much longer to reach a plateau $(\sim 200 \mathrm{~min}$; Fig. 1).

Testing variable concentrations of citric acid $(5,10,20 \mathrm{ppm})$ showed a proportional increase in induction time with increasing additive concentration (Fig. 2). The $6 \pm 1 \mathrm{~min}$ induction time observed in the pure $\mathrm{CaSO}_{4}$ system almost doubled in the presence of $5 \mathrm{ppm}$ citric acid $(10 \pm 1 \mathrm{~min})$, tripled with $10 \mathrm{ppm}(17 \pm 1 \mathrm{~min})$ and at $20 \mathrm{ppm}$ citric acid led to an induction time four times greater than that for the pure $\mathrm{CaSO}_{4}$ system $(25 \pm 1 \mathrm{~min})$.

The XRD analyses of the solids recovered at the end of each reaction (in both the pure and carboxylic acid-amended experiments) revealed that the sole mineral end product was gypsum. However, samples filter-quenched just after the onset of turbidity in the pure and citric acid system (e.g. after $30 \mathrm{~s}$ in the pure system and after

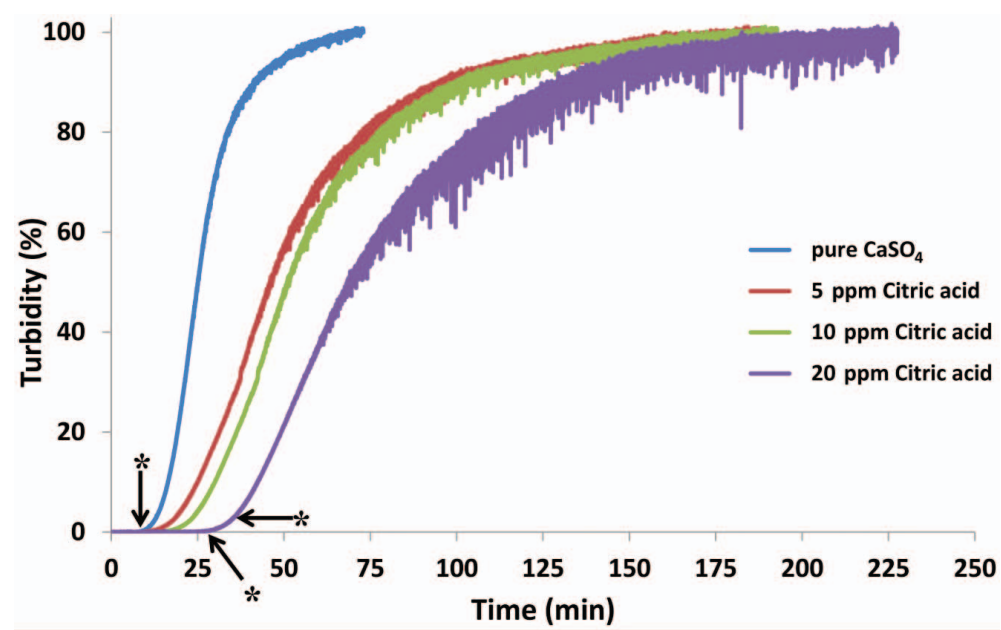

FIG. 2. The effect of variable concentrations of citric acid $(5,10,20 \mathrm{ppm})$ on the development of turbidity.

* Indicates the absolute times ( $\sim 7 \mathrm{~min}$ in the pure system and 28 and $35 \mathrm{~min}$, respectively, in the $20 \mathrm{ppm}$ citric acid system) when solids were removed and analysed. Data are shown in Figs $3 a, c, d$ and $4 a, c$. 
3 and $10 \mathrm{~min}$ in the presence of $20 \mathrm{ppm}$ citric acid; marked with * in Fig. 2 and corresponding to $\sim 7,26$ and $35 \mathrm{~min}$ in absolute time, respectively) showed in the XRD patterns the presence of bassanite coexisting with gypsum (Fig. $3 a, c)$. In both cases with time, the proportion of bassanite decreased (bassanite peaks decreased in intensity or disappeared completely) showing that bassanite was an intermediate phase (Fig. $3 d$ ) but that in both systems the final product was pure gypsum (Fig. 3b,e). As mentioned above, an increase in induction time prior to the onset of turbidity was also observed in the presence of the other two carboxylic acids (maleic and tartaric; Fig. 1). Although the shape and slope of the turbidity curves hint at a similar process, we do not have equivalent time-resolved XRD evidence that these additives also stabilized bassanite (but see below and Fig. 4e,f).

Photomicrographs of the intermediate $(\sim 7 \mathrm{~min}$, or $30 \mathrm{~s}$ after onset of turbidity) and end-product (after $70 \mathrm{~min}$ of total reaction) materials in the pure $\mathrm{CaSO}_{4}$ system revealed that bassanite was present at the beginning of the reaction only as elongated nanorods (up to $\sim 200 \mathrm{~nm}$ long) while at the end of the experiment only gypsum was present as larger (up to $\sim \mu \mathrm{m}$ size), thin, needlelike crystals, partly twinned (Fig. 4a,b). These morphologies and sizes are equivalent to those reported by Van Driessche et al. (2012) and Wang et al. (2013) and the presence of bassanite in our samples had already been documented through XRD (Fig. 3a,c). At the end of the pure systemcrystallization reaction (Fig. 4b) all bassanite had

FIG. 3. XRD patterns of precipitated materials from (a) the pure $\mathrm{CaSO}_{4}$ system removed from the reaction solution $30 \mathrm{~s}$ after turbidity onset (absolute time is $\sim 7 \mathrm{~min}$ ) with stars marking bassanite peaks of low intensity that are seen more easily in the insets, where the low-intensity (101) and (400) bassanite peaks are highlighted; (b) same system but 63 min after turbidity onset (absolute time $=70 \mathrm{~min}$ ) when the transformation to gypsum was complete and no bassanite remained; $(c-e)$ XRD patterns from the system with $20 \mathrm{ppm}$ citric acid added; (c) 3 min after turbidity onset (absolute time $=28 \mathrm{~min}$ ) showing all four distinct and very intense bassanite peaks - ((101), (200), (301) and (400) all marked with a star); (d) 10 min after turbidity onset (absolute time $=35 \mathrm{~min}$ ) showing smaller bassanite peaks; and (e) 175 min after turbidity onset (absolute time $=200 \mathrm{~min}$ ) where only gypsum peaks remain and all bassanite has been transformed. transformed and only large, elongated (between 5-50 $\mu \mathrm{m})$ needle-like and twinned gypsum crystals were present, again confirming the XRD data (Fig. $3 b$ ). In the presence of $20 \mathrm{ppm}$ citric acid, after the onset of turbidity ( $3 \mathrm{~min}, 28 \mathrm{~min}$ after mixing of the initial solutions) the bassanite identified by XRD (Fig. 3c) was present as very small but almost isometric nanoparticles

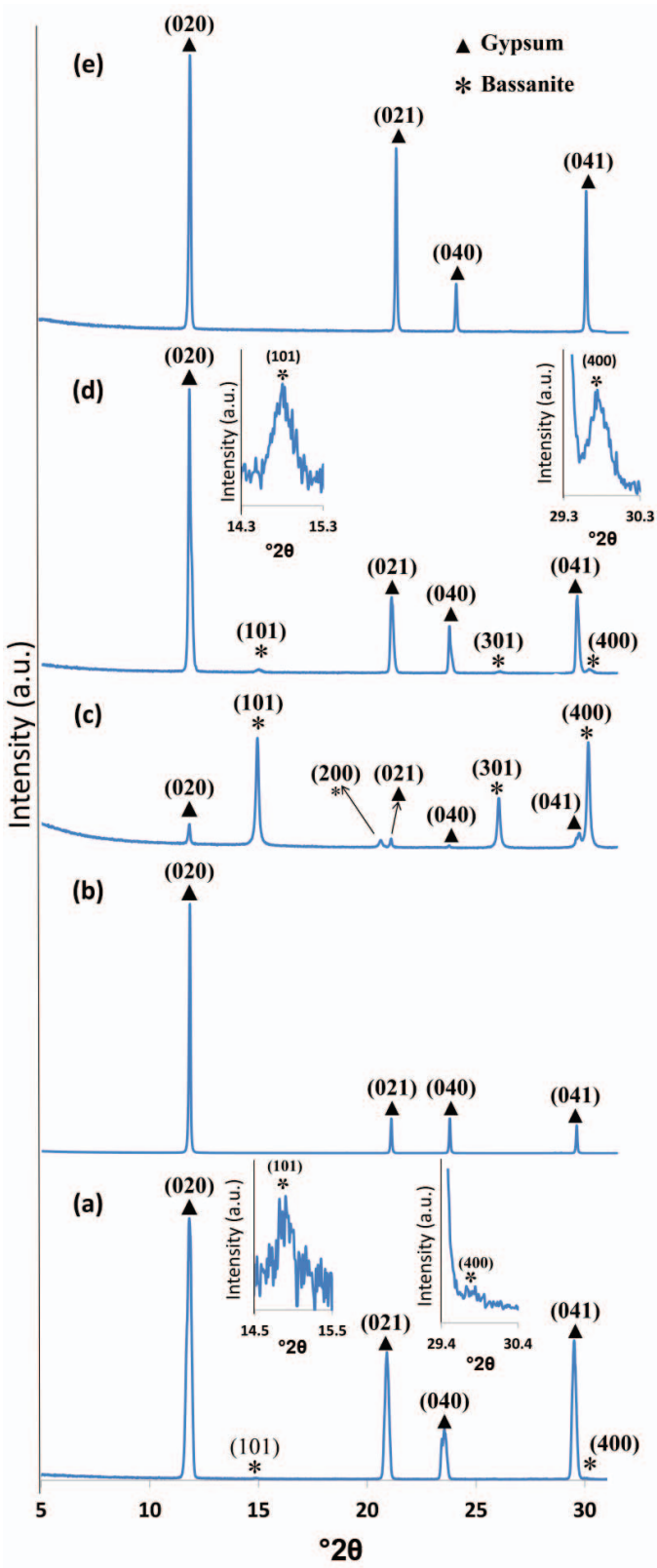




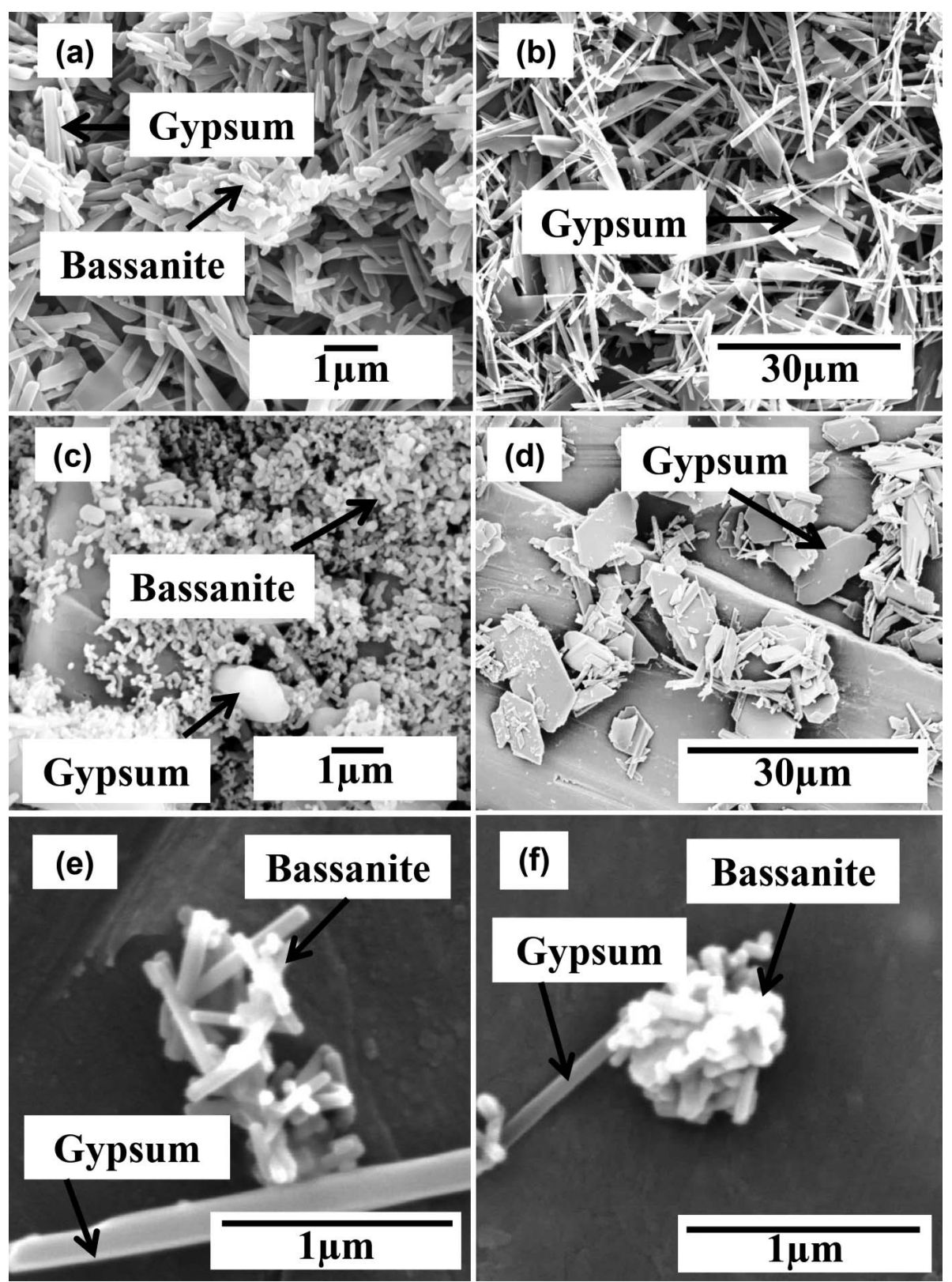

FIG. 4. SEM image of precipitated materials from experiments in: $(a)$ the pure $\mathrm{CaSO}_{4}$ system $30 \mathrm{~s}$ after turbidity onset showing bassanite nanorods and gypsum needles; $(b)$ the pure $\mathrm{CaSO}_{4}$ system 63 min after turbidity onset (70 minutes total time) showing only variably sized gypsum needles; (c) tiny bassanite nanoparticles formed in the presence of $20 \mathrm{ppm}$ citric acid 3 min after turbidity onset together with some larger gypsum crystals; $(d)$ plate-like gypsum crystals formed in the presence of $20 \mathrm{ppm}$ citric acid after $200 \mathrm{~min}$ of total reaction; (e) bassanite nanorods and a single larger gypsum needle collected a few minutes after the onset of turbidity in the $20 \mathrm{ppm}$ maleic acid experiment; $(f)$ bassanite nanorods and a single larger gypsum needle collected a few minutes after the onset of turbidity in the $20 \mathrm{ppm}$ tartaric acid experiment. 
$(<\sim 90 \mathrm{~nm}$; Fig. $4 c)$ that occurred together with larger gypsum crystals. At the end of the reaction, when the turbidity curve reached a plateau (after 200 min; Fig. 4d), only gypsum was present. It was striking that, compared to the pure $\mathrm{CaSO}_{4}$ system, both the bassanite and gypsum in the citrate system did not exhibit the typical bassanite nanorod or gypsum needle-like habits, but rather far more isomeric (bassanite; Fig. 4c) and distinctly platy (gypsum; Fig. 4d) habits. Although we have no XRD evidence of bassanite stabilization in the presence of maleic and tartaric acid, photomicrographs of samples removed a few minutes after the onset of turbidity in the $20 \mathrm{ppm}$ experiments with these carboxylic acids present revealed equivalent nanorod (particles $<200 \mathrm{~nm}$ ) morphologies that are inferred here to be bassanite. These occurred together with longer, needle-like crystals inferred to be gypsum (Fig. 4e,f). Contrary to the citric acid system however, in the presence of $20 \mathrm{ppm}$ tartaric or maleic acid, the shape, size or habit of the intermediate bassanite and end-product gypsum were the same as in the pure $\mathrm{CaSO}_{4}$ experiment, although a slight 'thinning' of the gypsum needles was observed.

\section{Discussion}

Measuring turbidity and estimating induction times in the absence and presence of additives is one of the most common methods of evaluating the efficiency of additives as a mechanism to delay the nucleation and growth of sparingly soluble scale minerals.

Additives that are biodegradable, such as the carboxylic acids used in the current study, and that delay dramatically the nucleation and or growth of a phase at low concentrations, are considered to be effective and are often referred to as 'inhibitors' although they do not inhibit nucleation and growth but most often just delay or change the reaction progress.

Our data revealed that at equal concentrations (20 ppm), among the three additives tested, citric acid increased the induction time and decreased the slope of the turbidity curve more than either of the tartaric and maleic acids, inferring that citric acid is, inherently, a better inhibitor. If we also consider the differences in molar concentrations of the carboxylic acids used: $C_{\mathrm{cit}}=1.01 \mu \mathrm{M} ; C_{\mathrm{tart}}$ $=1.33 \mu \mathrm{M} v$ s. $\left.C_{\mathrm{mal}}=1.72 \mu \mathrm{M}\right)$, these further support the fact that citric acid is the most effective inhibitor even though it is present in the lowest molar concentration. The reasons for its greater effectiveness are not yet clear but probably stem from the variations in molecular geometries and sorption capacities between these three carboxylic acids.

Additives can affect the nucleation and growth of scale minerals, e.g. by forming complexes or chelating agents with the active ions in the nucleating solutions (equation 1; where $x=2$ for maleic/tartaric acids or 3 for citric acid) or by sorbing to active crystal sites and inhibiting mineral growth (e.g. Crabtree et al., 1999; Badens et al., 1999; Ersen et al., 2006; Magallanes-Rivera et al., 2009).

$R(\mathrm{COOH})_{x}+\mathrm{Ca}^{2+} \rightarrow R(\mathrm{COOCa})_{x}+{ }_{x} \mathrm{H}^{+}$

In the case of the carboxylic acids tested, complexation with calcium is well known (Bazin et al., 1995) but sorption and growth inhibition also seem to play important roles. All carboxylic acids delayed the onset of nucleation (increased induction time compared to the pure system, Figs 1,2). The citric acid additive also affected the growth of the scale mineral, however, in that both bassanite and gypsum exhibited different habits compared to the additive-free phases (Fig. 4). Finally, of interest for mineral-scale formation and inhibition is the fact that, compared to the pure system, even low concentrations of citric acid stabilized the bassanite phase for much longer periods.

In additive experiments one of the fundamental parameters that controls 'inhibition' either through complexation with the active ions (in this case $\mathrm{Ca}^{2+}$ ) or sorption to active growth sites is the speciation and degree of protonation of the additive used. All our experiments with or without additives were carried out with the initial solutions adjusted to $\mathrm{pH} 7$. At this $\mathrm{pH}$ value all carboxylic acids are deprotonated to the largest extent (Table 1).

TABLE 1. Dissociation constants of the carboxylic acids used (from Lide, 1988).

\begin{tabular}{lccc}
\hline $\begin{array}{l}\text { Carboxylic } \\
\text { acid moiety }\end{array}$ & $\mathrm{pK}_{\mathrm{a} 1}$ & $\mathrm{pK}_{\mathrm{a} 2}$ & $\mathrm{pK}_{\mathrm{a} 3}$ \\
\hline Citric acid & 3.13 & 4.76 & 6.40 \\
Maleic acid & 1.92 & 6.23 & \\
Tartaric acid & 3.03 & 4.34 & \\
\hline
\end{tabular}


The delay in precipitation, indicated by the increased induction time, is probably due in part to $\mathrm{Ca}^{2+}$ complexation with these deprotonated species through the reduction of $\mathrm{Ca}^{2+}$ supersaturation. Of the carboxylic acids tested, citric acid at $\mathrm{pH} 7$ is the most deprotonated and may, therefore, act as the most efficient inhibitor, as reflected in the longest induction time. Nevertheless, the nucleation barrier in the presence of all additives is overcome and bassanite nucleates and eventually transforms to gypsum. The delay in precipitation in the presence of the carboxylic acid may also be attributed to sorption onto bassanite and gypsum growth sites. Badens et al. (1999) and Ersen et al. (2006) found that adsorption of citrate onto active growth faces of both bassanite and gypsum inhibited growth in those directions more than other carboxylic acid (e.g. tartaric or malic). This suggests that with citric acid, both bassanite and gypsum grew with different habits from those in the pure $\mathrm{CaSO}_{4}$ system, as the imaging data in the present study also confirmed (Fig. 4a,b). Citric acid seems to have inhibited growth along the $c$ axis and prevented the formation of typical long, needle-like habits. Instead, the growth of gypsum was favoured in the $a$ and $b$ directions, leading to platy crystal habits (Fig. 4). Similar morphological changes in gypsum habits in the presence of carboxylic acids have been reported by others $(\mathrm{Li}$ et al., 2007; Magallanes-Rivera et al., 2009) but a molecular-level understanding of the process is still lacking.

For gypsum formed in the presence of citric acid, Prisciandaro et al. (2005) showed that the increase in induction time was due to a dramatic change in interfacial tension compared to an additive-free system. Although the present study confirmed these findings, bassanite was also shown to be a metastable intermediate forming prior to gypsum not just in the pure $\mathrm{CaSO}_{4}$ system (Wang et al., 2012; Van Driessche et al., 2012) but also in the presence of carboxylic acids. In the pure system, bassanite forms below its thermodynamic bulk solubility and its transformation to gypsum is through hydration and self-assembly via a process controlled by a particle-sizedependent surface energy (Van Driessche et al., 2012). This is different from non-classical nucleation, growth and dehydration pathways suggested for calcium carbonates (Rodriguez Blanco et al., 2011; Bots et al., 2012) or calcium phosphates (Combes and Rey, 2010). The current study shows, however, that in the presence of even low concentrations of carboxylic acid: (1) the onset of the precipitation reaction is delayed; (2) bassanite is stabilized and its transformation to gypsum slowed; and (3) citric acid changes the shape and habit of the bassanite and gypsum formed.

If citric acid inhibitors are used in an industrialfluid handling system (where $\mathrm{CaSO}_{4}$ scale minerals are a problem) they can substantially retard nucleation and growth even at low concentrations. Importantly, citric acid may not just stabilize a nanoparticulate phase such as bassanite and thus reduce clogging of filters, but the size effect may also prevent adherence to pipe surfaces. However, this latter process and further growth of $\mathrm{CaSO}_{4}$ phases on surfaces is still under study.

\section{Acknowledgements}

This study was supported by the Marie Curie grant from the European Commission in the framework of the MINSC ITN (Initial Training Research network), Project number 290040. The authors thank the Cohen Laboratories in the School of Earth and Environment, and the Leeds Electron Microscopy and Spectroscopy Centre (LEMAS) for help and access to instruments during the course of this study. They also thank three reviewers and the associate editor for their constructive comments, which helped to improve the paper.

\section{References}

Akyol, E., Oner, M., Barouda, E. and Demadis, K.D. (2009) Systematic structural determinants of the effects of tetraphosphonates on gypsum crystallization. Crystal Growth \& Design, 9, 5145-5154.

Amjad, Z. and Koutsoukos, P.G. (2014) Evaluation of maleic acid based polymers as scale inhibitors and dispersants for industrial water applications. Desalination, 335, 55-63.

Badens, E., Veesler, S. and Boistelle, R. (1999) Crystallization of gypsum from hemihydrate in presence of additives. Journal of Crystal Growth, 198, 704-709.

Bazin, H., Bouchu, A., Descotes, G. and Petit-Ramel, M. (1995) Comparison of calcium complexation of some carboxylic acids derived from D-glucose and D-fructose. Canadian Journal of Chemistry, 73, 1338-1347.

Bots, P., Rodriguez-Blanco, J.D., Roncal-Herrero, H., Shaw, S. and Benning, L. (2012) Mechanistic insights into the crystallization of amorphous 
calcium carbonate (ACC). Crystal Growth \& Design, 12, 3806-3814.

Camarini, G. and De Milito, J.A. (2011) Gypsum hemihydrate-cement blends to improve renderings durability. Construction and Building Materials, 25, 4121-4125.

Cao, K., Zhou, Y., Liu, G., Wang, H. and Sun, W. (2014) Preparation and properties of a polyetherbased polycarboxylate as an antiscalant for gypsum. Journal of Applied Polymer Science, 131, 1-9.

Combes, C. and Rey, C. (2010) Amorphous calcium phosphates: synthesis, properties and uses in biomaterials. Acta Biomaterialia, 6, 3362-3378.

Crabtree, M., Slinger, D., Fletcher, P., Miller, M., Johnson, A. and King, G. (1999) Fighting scale removal and prevention. Oilfield Review, 11, 30-45.

Ersen, A., Smith, A. and Chotard, T. (2006) Effect of malic and citric acid on the crystallisation of gypsum investigated by coupled acoustic emission and electrical conductivity techniques. Journal of Materials Science, 41, 7210-7217.

Freyer, D. and Voigt, W. (2003) Crystallization and phase stability of $\mathrm{CaSO}_{4}$ and $\mathrm{CaSO}_{4}$-based salts. Monatshefte für Chemie/Chemical Monthly, 134, $693-719$.

Guan, B., Yang, L. and Wu, Z. (2010) Effect of $\mathrm{Mg}^{2+}$ ions on the nucleation kinetics of calcium sulfate in concentrated calcium chloride solutions. Industrial \& Engineering Chemistry Research, 49, 5569-5574.

Hasson, D., Shemer, H. and Sher, A. (2011) State of the art of friendly "Green" scale control inhibitors: a review article. Industrial \& Engineering Chemistry Research, 50, 7601-7607.

Kinsman, D.J. (1969) Modes of formation, sedimentary associations and diagnostic features of shallow-water and supratidal evaporites. The American Association of Petroleum Geologists Bulletin, 53, 830-840.

Li, J., Li, G. and Yu, Y. (2007) The influences of gypsum water-proofing additive on gypsum crystal growth. Materials Letters, 61, 872-876.

Lide, D.R., editor (1988) CRC Handbook of Chemistry and Physics. CRC Press, Boca Raton, Florida, USA, 88, chapter 8, p. 49.

Ling, L., Zhou, Y., Huang, J., Yao, Q., Liu, G., Zhang, P., Sun, W. and Wu, W. (2012) Carboxylateterminated double-hydrophilic block copolymer as an effective and environmental inhibitor in cooling water systems. Desalination, 304, 33-40.

Magallanes-Rivera, R.X., Escalante-Garcia, J.I. and Gorokhovsky, A. (2009) Hydration reactions and microstructural characteristics of hemihydrate with citric and malic acid. Construction and Building Materials, 23, 1298-1305.
Mi, B. and Elimelech, M. (2010) Gypsum scaling and cleaning in forward osmosis: measurements and mechanisms. Environmental Science \& Technology, 44, 2022-2028.

Moghadasi, J., Sharif, A., Müller-Steinhagen, H. and Jamialahmadi, M. (2006) Prediction of scale formation problems in oil reservoirs and production equipment due to injection of incompatible waters. Developments in Chemical Engineering and Mineral Processing, 14, 545-566.

Parkhurst, D.L. and Appelo, C.A.J. (1999) User's guide to PHREEQC (Version 2): A computer program for speciation, batch-reaction, one-dimensional transport, and inverse geochemical calculations. US Geological Survey Water Resource Investigation. Report 99-4259, 312 pp.

Prisciandaro, M., Santucci, A., Lancia, A. and Musmarra, D. (2005) Role of citric acid in delaying gypsum precipitation. The Canadian Journal of Chemical Engineering, 83, 586-592.

Rahardianto, A., Mccool, C.B. and Cohen, Y. (2008) Reverse osmosis desalting of inland brackish water of high gypsum scaling propensity: kinetics and mitigation of membrane mineral scaling. Environmental Science \& Technology, 42, 4292-4297.

Rodriguez-Blanco, J.D., Shaw, S. and Benning, L.G. (2011) The kinetics and mechanisms of amorphous calcium carbonate (ACC) crystallization to calcite, via vaterite. Nanoscale, 3, 265-271.

Senthilmurugan, B., Ghosh, B., Kundu, S.S., Haroun, M. and Kameshwari, B. (2010) Maleic acid based scale inhibitors for calcium sulfate scale inhibition in high temperature application. Journal of Petroleum Science and Engineering, 75, 189-195.

Shakkthivel, P. and Vasudevan. T. (2006) Acrylic aciddiphenylamine sulphonic acid copolymer threshold inhibitor for sulphate and carbonate scales in cooling water systems. Desalination, 197, 179-189.

Van Driessche, A.E.S., Benning, L.G., RodriguezBlanco, J.D., Ossorio, M., Bots, P. and GarciaRuiz, J.M. (2012) The role and implications of bassanite as a stable precursor phase to gypsum precipitation. Science, 336, 69-72.

Wang, Y.W., Kim, Y.Y., Christenson, H.K. and Meldrum, F.C. (2012) A new precipitation pathway for calcium sulfate dihydrate (gypsum) via amorphous and hemihydrate intermediates. Chemical Communications, 48, 504-506.

Wang, Y.W., Christenson, H.K. and Meldrum, F.C. (2013) Confinement leads to control over calcium sulfate polymorph. Advanced Functional Materials, 23, 5615-5623. 